\title{
Open Wedge High Tibial Osteotomy Distal to the Tibial Tuberosity, is it a Superior Alternative? Review of the Literature
}

\section{Sarmad Rashed Khalil Sulaiman*, Naif Mohammed Al Junaid, Meshal Yousef Koshok and Rayan Mohammed Taher Al Arabi}

Department of Orthopaedic Surgery, Al Madina Al Munawara Hospital, Saudi Arabia

*Corresponding Author: Sarmad Rashed Khalil Sulaiman, Department of

Orthopaedic Surgery, Al Madina Al Munawara Hospital, Saudi Arabia.
Received: November 20, 2020

Published: December 10, 2020

(C) All rights are reserved by Sarmad

Rashed Khalil Sulaiman., et al.

\section{Abstract}

Open wedge high tibial osteotomy is a successful surgical procedure for the medial compartment knee osteoarthritis. It is a highly useful method in correcting the deformity and reducing the pain for better function, therefore, potentially delaying the need for knee arthroplasty. However, changes in the patellofemoral biomechanics due to patella infera could raise unusual patellofemoral contact pressures that generate patellofemoral osteoarthritis. Furthermore, the conversion of high tibial osteotomy to total knee replacement is a technical challenge. Open wedge osteotomy distal to the tibial tuberosity does not compromise the patellofemoral biomechanics; therefore, could be a preferable alternative.

The current literature review aims to answer the question: Is the open wedge osteotomy distal to the tibial tuberosity a superior alternative to the conventional high tibial osteotomy? There will be an evaluation of the open wedge osteotomy distal to the tibial tuberosity in comparison with the traditional open wedge osteotomy proximal to the tibial tuberosity in terms of alteration in, patellar height, patellar tilt, patellar shift, posterior tibial slope, patellofemoral arthrosis, tibial tuberosity fracture, nonunion rate, the influence on subsequent total knee replacement.

Keywords: High Tibial Osteotomy; Open Wedge Osteotomy; Tibial Tubercle; Tibial Tuberosity; Medial Compartment Osteoarthritis; Genu Varum

\section{Introduction}

High tibial osteotomy (HTO) as a treatment for medial compartment knee osteoarthritis (MCKO) was born with Langenbeck in 1854, Jackson initially reported the technique in 1958, and in 1973 was popularized by Coventry $[1,2]$. Opening wedge high tibial osteotomy technique (OWHTO) is increasingly applied to preserve the knee medial compartment from further joint degeneration, with satisfactory outcomes for biomechanical, radiographical, and reported patients' results, particularly in active young patients with an intact knee lateral compartment [3]. Lower limb malalignment is believed to play a crucial role by putting aberrant stresses on the articular cartilage. During the stance phase in a normal aligned knee, approximately $55-70 \%$ of the load was transmitted to the knee medial compartment in the coronal plane [4]. With the varus deformity, the load on the knee medial compartment will increase by five percent for each one-degree varus deviated from the neutral alignment, and more than two degrees varus, significantly accelerate the development of knee osteoarthritis in a brief period of time $[4,5]$.

OWHTO corrects the mechanical axis by sidestepping the joint degenerated segment to the relatively normal compartment $[4,5]$. The correct weight-bearing axis should be placed at a point $62 \%$ of the proximal tibia total width from medial to lateral [6]. Generally, the technique gives adequate pain relief and functional restoration in approximately $80 \%$ to $90 \%$ of patients after five years of the surgery, and $50 \%$ to $65 \%$ after ten years [7]. The result of the OWHTO can be enhanced if particular attention is paid to appropriate pa- 
tient selection concerning body mass index, age, and knee range of motion (ROM) [8].

In the conventional OWHTO procedure, the tibial tuberosity stays attached to the distal part of the tibia, because the osteotomy is proximal to the tibial tuberosity. When the wedge is opened, the joint line will be elevated, and subsequently, the quadriceps angle $(\mathrm{QA})$, the patellar height ( $\mathrm{PH})$, and the axial axes of the patella will be changed. On the other hand, with the opening wedge osteotomy distal to the tibial tuberosity (OWODTT) the tuberosity remains connected to the proximal part of the tibia, and there will be a minimum alteration in the QA, and the patellar position after the wedge is opened [8-10]. Additionally, the tibial plateau inclination in the sagittal plane is changing more with OWHTO than with OWODTT, consequently there will be more alteration in the patellar height [11-14]. Reduced PH leads to patellofemoral problems and could complicate the conversion to total knee replacement (TKR) when the knee osteoarthritis become worse $[15,16]$. The primary TKA surgical technique after OWHTO is complicated and less successful than where OWHTO has not been performed [17-21].

This review article will focus on answering the question: Is the open wedge osteotomy distal to the tibial tuberosity a superior alternative to the conventional high tibial osteotomy? There will be an evaluation of the open wedge osteotomy distal to the tibial tuberosity in comparison with the traditional open wedge osteotomy proximal to the tibial tuberosity in terms of alteration in, patellar height, patellar tilt, patellar shift, posterior tibial slope, patellofemoral arthrosis, nonunion rate, the influence on subsequent total knee replacement.

\section{Methodology}

The literature was reviewed by searching the PubMed using the keywords: High tibial osteotomy, open wedge osteotomy, which were subsequently matched with search terms: Medial compartment osteoarthritis, tibial tubercle, tibial tuberosity, genu varum. The review inclusion criteria included: (1) Published articles which written only in English between 2000 to 2020, (2) Randomized-controlled trials, longitudinal cohort and retrospective studies, prospective studies, case series (3) Assessment of surgical results of open wedge high tibial osteotomy below tuberosity uniplanar or biplanar, fixed with plate and screws, (4) Patients with medial compartment osteoarthritis and varus malalignment. Exclusion criteria included: (1) Results of other techniques of the high tibial osteotomy. (2) Study population with the majority being pediatric patients. The search result was 710 articles. The articles were scanned by the titles and the published abstracts, to exclude the non-relevant articles, the result was 70 articles. After exclusion of duplicated articles, the result was 27 . The search was ended with fifteen studies after full article review (Figure 1), with a total of 521 patients and 551 below tibial tuberosity osteotomies. The studies characteristics were summarized in (Table 1).

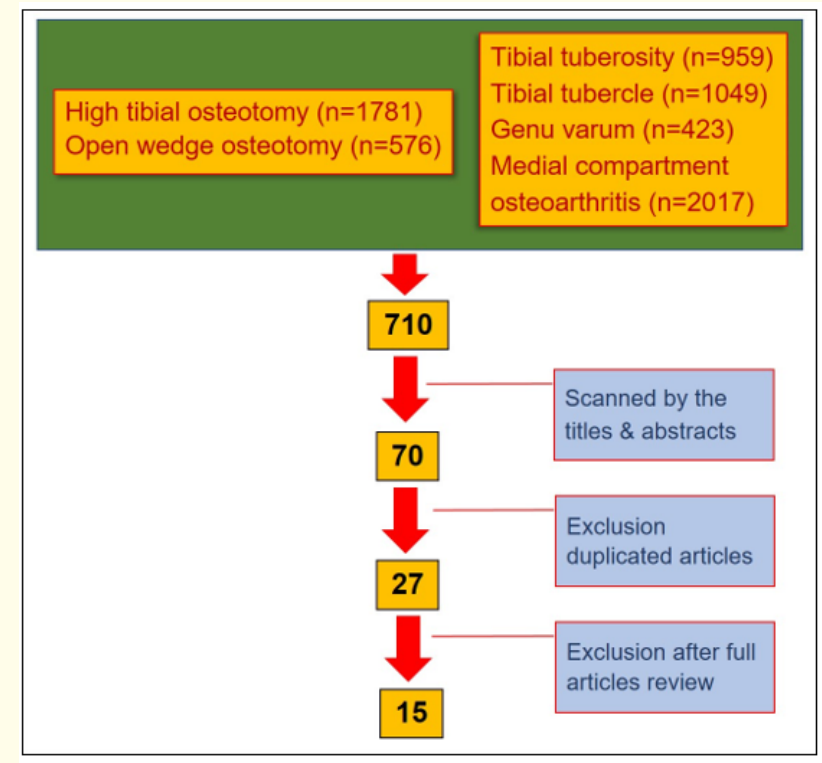

Figure 1

\section{Discussion}

Conventional OWHTO continues to be an important and durable solution for the MCKO in an active young patient instead of knee replacement surgery. The long-term joint outcome is depending on the correction of the osteotomy in the coronal plane by shifting the mechanical weight from the overloaded and degenerated knee medial compartment to the intact knee lateral compartment, for an effort to improve the force distribution across the knee joint $[1,4,5,8,21]$. While this procedure directly impacts the femorotibial joint, it influences the patellofemoral joint indirectly by alteration in the patella position [21]. The variation in patella position could be because of changes in the $\mathrm{PH}$, the posterior tibial slope (PTS, described as the angle created between a line perpendicular to the axis of the tibial shaft and the medial tibial plateau) [22], the lateral patellar tilt (LPT), the lateral patellar shift (LPS) or the displacement of the tibial tuberosity after the osteotomy. 
Several studies in the literature investigated or organized a comparison between OWHTO and OWODTT, regarding their influence on PH, PTS, patellar, and shift [1,2,8-10,12-14,16,23-25]. Additionally, arthroscopic studies were conducted to evaluate the patellofemoral joint cartilage after both procedures [14,25].

The reduction in $\mathrm{PH}$ (Patella infera) is a consequence of OWHTO; this has been occurred becaused of joint line elevation, patellar tendon contracture, or change in the PTS in relation to the static position of the patella $[11,12,15]$. During the conventional OWHTO, the opening wedge is superior to the tibial tuberosity, which leads to large distal and lateral displacement of the tibial tuberosity and the patellar tendon, thus, the patella height is decreased relative to the joint line, which significantly changes the extensor mechanism force and can create substantial mechanical stress on the patella $[1,11-13,15]$. The extent of the tibial tuberosity displacement is proportionate to the degree of the wedge opening, which in turns leads to patella infera $[13,26]$. Shortening of the patellar tendon is another factor triggering the patella infera, and that was attributed to the proximity of the osteotomy site to the patellar tendon and the infrapatellar fat pad which resulted in scaring and adherence of the patellar tendon to the proximal tibia $[12,13,16]$.

On the other hand, patella infera could result when the PTS increases after OWHTO, with an average of two degrees to five degrees $[8-10,12,13,27]$. Another drawback of increasing in the PTS, is its effect on the tibial anteroposterior translation as well as straining forces on the anterior cruciate ligament (ACL) and therefore the influence on knee kinematics and stability which might be a risk factor for ACL injuries [10,12,13,24,28]. It should be noted that there are recommendations and strategies for OWHTO to minimize PTS changes by controlling the osteotomy gap [8,29-32].

Previous studies have demonstrated that the alteration in the patellar axial alignment was significant for LPT and not for LPS with OWHTO or OWODTT $[23,33,34]$. That was attributed to the accretion of the lateral pull on the patella, probably explained by the shifting in the mechanical axis that could influence the patellar axial alignment [23]. Furthermore, the tibial rotation after OWHTO may play a role in changing the LPT $[8,34,35]$.

The change in the patellar position alters the natural biomechanics and consequently the contact stresses of the patellofemoral joint, potentially commencing or accelerating the patellofemoral osteoarthritis, which leads to knee pain, crepitus and limitation the knee range of motion as demonstrated in the earlier studies $[1,12,13,16,33]$. On the other hand, an increase in PTS could result in a posterior shifting of the intraarticular cartilage pressure, generating a knee pain [10]. This alteration will be higher when attempting to correct a considerable angular varus deformity, more than five degrees, in the coronal plane $[12,13,36,37]$. The solution to deal with this issue is by lowering the risk of patella infera, which subsequently will prevent the biomechanical problems with the patellofemoral joint [11]. Cadaveric studies have been determined that OWODTT had no significant effect on the patellofemoral cartilage pressure in contrast with OWHTO [25,37,39].

Performing an OWODTT has been recommended as a strategy to prevent the change in the patellar position [1,2,8-10,12-14,16,2325]. In OWODTT, when the osteotomy site opens, the PH stays unchanged because the tibial tuberosity remains connected to the proximal tibial portion; hence, the patella is maintaining its position in relation to the tibiofemoral joint line $[1,2,8-10,12,14,16,23,24]$. Furthermore, different studies have been revealed that with OWODTT, there was no increase in the PTS, therefore no change in ACL balance $[2,8-10,12,13,23,24]$. Another evident advantage of OWODTT is that the minimal risk of patellar tendon scaring or adherence to proximal tibia which make the forthcoming TKR technically less demanding, contrary to OWHTO that has been elucidated to be less successful and more complicated than TKR which has not been preceded by OWHTO $[17,18]$. The proximal tibia exposure and the patellar eversion remain challenging, and the risk of tibial tuberosity avulsion will be high $[12,13,16,38]$.

Arthroscopic comparative studies were arranged to evaluate the patellofemoral cartilage before the osteotomy and at the time of implant removal for patients who underwent both OWHTO and OWODTT $[14,25]$ In one study, $84.8 \%$ of the patients who underwent OWODTT did not demonstrate signs of progression of cartilage degradation in the patellofemoral, and $10.9 \%$ of the patient shown improvement [14]. In contrast, $31.4 \%$ of the patients who underwent OWHTO showed high patellofemoral cartilage degradation [14]. There was a significant variation in the progression of PF cartilage degradation between OWODTT and OWHTO [14,25]. OWODTT leads to reduce the worsening and enhance the improvement of macroscopic patellofemoral joint cartilage condition and better clinical result $[14,25]$.

Several studies revealed the significant improvement in the clinical and the functional outcome with OWODTT which were 
evaluated by using different scores and scales, such as the knee society score, hospital for Special Surgery score, Lysholm knee score, Oxford score, international knee documentation committee score, Kujala anterior knee pain scale, and Tegner score $[1,9,13,14,24,25,38,40]$. In a comparative study, the clinical and the functional outcome were found to be better in OWODTT group than OWHTO group, and that were attributed to the patella infera and the proximity of the osteotomy in OWHTO to the richly innervated infrapatellar fat pad, which could cause anterior knee pain [25].

Some concerns were raised regarding relocating the osteotomy distal to the tibial tuberosity that will potentiate the risk of delay, nonunion, or tibial tuberosity fracture. After reviewing the literature, we realized that in 423 OWODTT performed the delay, and the nonunion have been occurred in $1.6 \%$ (Table 1). We believe that with this low percentage, the delay and nonunion are not considered as a serious complication to withdraw from performing OWODTT. Fracture of the tibial tuberosity could happen with the biplanar type OWODTT, and it seems to be related to the surgical technique rather than the degree of varus correction $[9,23]$. The tibial tuberosity fracture can be avoided by increasing the thickness of the tibial tuberosity one centimeter or more [9,23]. Another fracture, lateral hinge fracture, could take place with both types of HTO, below or above the tibial tuberosity, and may be a cause of nonunion [41]. It is more frequent with biplanar type of the osteotomy [41]. Previous studies have been described the association between lateral hinge fracture and the hinge location $[41,42]$. Appropriate hinge positioning is essential for avoidance of the lateral hinge fracture $[41,42]$.

From the advantages mentioned, we believe that the open wedge osteotomy distal to the tibial tuberosity is a superior technique to the standard open wedge high tibial osteotomy.

There were limitations to this study. The search include only papers which were written in English. The search did not include earlier papers than 2000, and other papers that are not on Pubmed.

Figure 1: Showing the flowchart of searching process.

\begin{tabular}{|c|c|c|c|c|c|c|c|c|c|c|c|}
\hline \multicolumn{12}{|c|}{ Data summary } \\
\hline Authors & $\begin{array}{l}\text { Publi- } \\
\text { cation } \\
\text { Date }\end{array}$ & Study design & $\begin{array}{c}\text { Study } \\
\text { Purpose }\end{array}$ & $\begin{array}{c}\text { No. of } \\
\text { Pa- } \\
\text { tients }\end{array}$ & $\begin{array}{c}\text { No. } \\
\text { of } \\
\text { oste- } \\
\text { oto- } \\
\text { mies }\end{array}$ & $\begin{array}{l}\text { Pa- } \\
\text { tients } \\
\text { age } \\
\text { (Year) }\end{array}$ & $\begin{array}{l}\text { Operative } \\
\text { Tech- } \\
\text { nique }\end{array}$ & $\begin{array}{l}\text { Bone } \\
\text { graft }\end{array}$ & $\begin{array}{l}\text { Follow- } \\
\text { up } \\
\text { (month) }\end{array}$ & $\begin{array}{c}\text { Delay/ } \\
\text { Nonunion }\end{array}$ & TT Fx \\
\hline $\begin{array}{l}\text { Gaas- } \\
\text { beek., et } \\
\text { al. [16] }\end{array}$ & 2004 & $\begin{array}{l}\text { Prospective } \\
\text { Comparative } \\
\text { with histori- } \\
\text { cal group }\end{array}$ & $\mathrm{PH}$ & 17 & 17 & $27-64$ & $\begin{array}{l}\text { Biplanar } \\
\text { Osteotomy }\end{array}$ & $\begin{array}{c}\text { Tri- } \\
\text { calcium } \\
\text { phosphate }\end{array}$ & $\begin{array}{l}\text { Not } \\
\text { men- } \\
\text { tioned }\end{array}$ & 1 & 1 \\
\hline $\begin{array}{l}\text { Hooper., } \\
\text { et al. [38] }\end{array}$ & 2005 & $\begin{array}{c}\text { Prospective } \\
\text { study }\end{array}$ & $\begin{array}{l}\text { Clinical } \\
\text { evalua- } \\
\text { tion, WBL } \\
\text { and FTA }\end{array}$ & 44 & 45 & $31-66$ & $\begin{array}{l}\text { Oblique } \\
\text { Uniplanar }\end{array}$ & $\begin{array}{l}\text { Autoge- } \\
\text { nous/sub- } \\
\text { stitutes }\end{array}$ & $7-74$ & 3 & 0 \\
\hline $\begin{array}{l}\text { Keyhani., } \\
\text { et al. [2] }\end{array}$ & 2011 & $\begin{array}{c}\text { Randomize } \\
\text { controlled } \\
\text { trial }\end{array}$ & $\begin{array}{l}\text { PH and } \\
\text { PTS }\end{array}$ & 34 & 34 & $\begin{array}{c}28.1 \pm \\
2.7\end{array}$ & $\begin{array}{l}\text { Biplanar } \\
\text { Osteotomy }\end{array}$ & $\begin{array}{l}\text { Autog- } \\
\text { enous }\end{array}$ & $10-21$ & 0 & 0 \\
\hline $\begin{array}{l}\text { Hinter- } \\
\text { wimmer., } \\
\text { et al. [8] }\end{array}$ & 2011 & $\begin{array}{l}\text { Prospective } \\
\text { Case Series }\end{array}$ & $\begin{array}{l}\text { PH and } \\
\text { PTS }\end{array}$ & 12 & 12 & $\begin{array}{c}42.8 \pm \\
9.6\end{array}$ & $\begin{array}{l}\text { Biplanar } \\
\text { Osteotomy }\end{array}$ & $\begin{array}{c}\text { Not } \\
\text { men- } \\
\text { tioned }\end{array}$ & $\begin{array}{c}\text { Not } \\
\text { men- } \\
\text { tioned }\end{array}$ & $\begin{array}{l}\text { Not } \\
\text { menti- } \\
\text { oned }\end{array}$ & $\begin{array}{l}\text { Not } \\
\text { men- } \\
\text { tioned }\end{array}$ \\
\hline $\begin{array}{l}\text { Shim., et } \\
\text { al. [13] }\end{array}$ & 2013 & $\begin{array}{l}\text { Retrospective } \\
\text { Study }\end{array}$ & $\begin{array}{l}\text { Clinical } \\
\text { evalua- } \\
\text { tion, PH } \\
\text { and PTS }\end{array}$ & 19 & 37 & $16-45$ & $\begin{array}{l}\text { Oblique } \\
\text { Uniplanar }\end{array}$ & $\begin{array}{l}\text { Autog- } \\
\text { enous }\end{array}$ & $12-108$ & 1 & 0 \\
\hline $\begin{array}{l}\text { Longino., } \\
\text { et al. [12] }\end{array}$ & 2013 & $\begin{array}{l}\text { Prospective } \\
\text { Cohort Study } \\
\text { with Histori- } \\
\text { cal Controls }\end{array}$ & $\begin{array}{l}\text { PH and } \\
\text { PTS }\end{array}$ & 29 & 29 & $38-54$ & $\begin{array}{l}\text { Biplanar } \\
\text { Osteotomy }\end{array}$ & $\begin{array}{c}\text { Cancel- } \\
\text { lous Al- } \\
\text { lograft }\end{array}$ & 36 & 1 & 0 \\
\hline
\end{tabular}




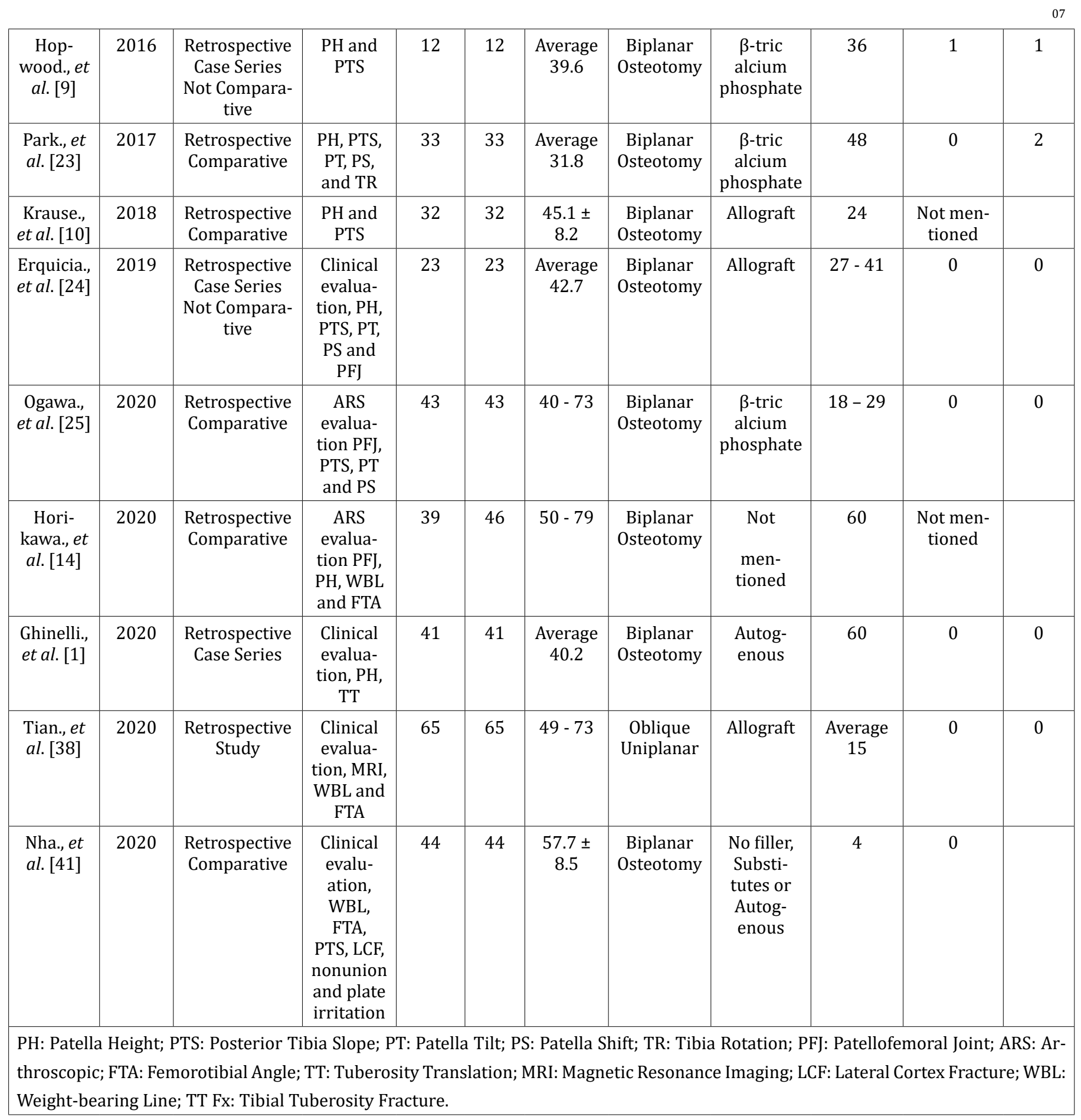

\section{Conclusion}

Performing the open wedge osteotomy distal to the tibial tuberosity has been demonstrated to be useful in treating the varus knee deformity and the medial compartment knee osteoarthritis with maintaining of the preoperative patellar position relative to the tibiofemoral joint line, contrary to the standard open wedge high tibial osteotomy. 
The open wedge osteotomy distal to the tibial tuberosity prevented the deterioration of patellofemoral cartilage degeneration and increased the improvement of cartilage condition, which is proven to be a possible problem after the standard open wedge high tibial osteotomy.

The open wedge osteotomy distal to the tibial tuberosity showed to be able to achieve significant improvement in the clinical and the radiological results.

\section{Acknowledgments}

No acknowledgments.

\section{Financial Support and Sponsorship}

This study did not receive any specific grant from funding agencies in the public, commercial, or not-for-profit sectors.

\section{Conflicts of Interest}

There are no conflicts of interest.

\section{Authors' Contributions}

RA conceived and designed the study and wrote the initial draft of the article. NA and MK collected, organized, banalysis and interpretation of the data. SS provided critical revision and wrote the final draft of the article. All authors have critically reviewed and approved the final draft and are responsible for the manuscript's content and similarity index.

\section{Bibliography}

1. Ghinelli D., et al. "Five years of clinical and radiological results with biplanar tibial open-wedge osteotomy: feasible option to prevent patella infera?" European Journal of Orthopaedic Surgery and Traumatology (2020): 1-9.

2. Keyhani S., et al. "Modified retro-tubercle opening-wedge versus conventional high tibial osteotomy". Orthopedics 34.2 (2011): 90.

3. Birmingham TB., et al. "Medial opening wedge high tibial osteotomy: a prospective cohort study of gait, radiographic, and patient-reported outcomes". Arthritis Care and Research: Official Journal of the American College of Rheumatology 61.5 (2009): 648-657.

4. Liu X., et al. "High tibial osteotomy: review of techniques and biomechanics". Journal of Healthcare Engineering (2019): 1-12.
5. Halder A., et al. "Influence of limb alignment on mediolateral loading in total knee replacement: in vivo measurements in five patients". JBJS 94.11 (2012): 1023-1029.

6. Fujisawa YO., et al. "The effect of high tibial osteotomy on osteoarthritis of the knee. An arthroscopic study of 54 knee joints". The Orthopedic clinics of North America 10.3 (1979): 585.

7. Zhang HN., et al. "Modified biplanar open-wedge high tibial osteotomy with rigid locking plate to treat varus knee". Journal of Zhejiang University Science B 10.9 (2009): 689-695.

8. Hinterwimmer S., et al. "Control of posterior tibial slope and patellar height in open-wedge valgus high tibial osteotomy". The American Journal of Sports Medicine 39.4 (2011): 851-856.

9. Hopwood S., et al. "The biplanar open wedge high tibial osteotomy preserving the tibial tubercle". Journal of Orthopaedic Science 21.6 (2016): 786-790.

10. Krause M., et al. "Patella height is not altered by descending medial open-wedge high tibial osteotomy (HTO) compared to ascending HTO". Knee Surgery, Sports Traumatology, Arthroscopy 26.6 (2018): 1859-1866.

11. Kaper BP., et al. "Patellar infera after high tibial osteotomy". Journal of Arthroplasty 16.2 (2001): 168-173.

12. Longino PD., et al. "Combined tibial tubercle osteotomy with medial opening wedge high tibial osteotomy minimizes changes in patellar height: a prospective cohort study with historical controls". American Journal of Sports Medicine 41.12 (2013): 2849-2857.

13. Shim JS., et al. "High tibial open wedge osteotomy below the tibial tubercle: clinical and radiographic results". Knee Surgery, Sports Traumatology, Arthroscopy 21.1 (2013): 57-63.

14. Horikawa T., et al. "Distal tuberosity osteotomy in open-wedge high tibial osteotomy does not exacerbate patellofemoral osteoarthritis on arthroscopic evaluation". Knee Surgery, Sports Traumatology, Arthroscopy 28.6 (2020): 1750-1756.

15. Wright JM., et al. "Observations on patellar height following opening wedge proximal tibial osteotomy". American Journal of Knee Surgery 14.3 (2001): 163-173.

16. Gaasbeek RD., et al. "Distal tuberosity osteotomy in open wedge high tibial osteotomy can prevent patella infera: a new technique". Knee 11.6 (2004): 457-461. 
17. Mont MA., et al. "Total knee arthroplasty after failed high tibial osteotomy. A comparison with a matched group". Clinical Orthopaedics and Related Research 299 (1994): 125-130.

18. Haddad FS and Bentley G. "Total knee arthroplasty after high tibial osteotomy: a medium-term review". Journal of Arthroplasty 15 (2000): 597-603.

19. Meding JB., et al. "Total knee arthroplasty after high tibial osteotomy". Clinical Orthopaedics and Related Research 375 (2000): 175-184.

20. Windsor RE., et al. "Technical considerations of total knee arthroplasty after proximal tibial osteotomy". The Bone and Joint Journal 70A (1988): 547-555.

21. Closkey RF and Windsor RE. "Alterations in the patella after a high tibial or distal femoral osteotomy". Clinical Orthopaedics and Related Research 389 (2001): 51-56.

22. Oswald MH., et al. "Radiological analysis of normal axial alignment of femur and tibia in view of total knee arthroplasty". Journal of Arthroplasty 8 (1993): 419-426.

23. Park H., et al. "Open Wedge High Tibial Osteotomy with Distal Tubercle Osteotomy Lessens Change in Patellar Position". BioMed Research International 2017 (2017): 4636809.

24. Erquicia J., et al. "Biplane opening wedge high tibial osteotomy with a distal tuberosity osteotomy, radiological and clinical analysis with minimum follow-up of 2 years". Journal of Experimental Orthopaedics 6.1 (2019): 10.

25. Ogawa H., et al. "Distal tibial tubercle osteotomy is superior to the proximal one for progression of patellofemoral osteoarthritis in medial opening wedge high tibial osteotomy". Knee Surgery, Sports Traumatology, Arthroscopy 28.20 (2020): 3270-3278.

26. Chae DJ., et al. "Tibial slope and patellar height after opening wedge high tibial osteotomy using autologous tricortical iliac bone graft". Knee 15.2 (2008): 128e33.

27. LaPrade RF., et al. "Patellar height and tibial slope after opening-wedge proximal tibial osteotomy: a prospective study". The American Journal of Sports Medicine 38.1 (2010): 160170.

28. Feucht MJ., et al. "The role of the tibial slope in sustaining and treating anterior cruciate ligament injuries". Knee Surgery, Sports Traumatology, Arthroscopy 21.1 (2013): 134-145 .
29. Noyes FR., et al. "The early diagnosis and treatment of developmental patella infera syndrome". Clinical Orthopaedics and Related Research 265 (1991): 241-252.

30. Hernigou P. “Open wedge tibial osteotomy: combined coronal and sagittal correction". Knee 9 (2002): 15-20.

31. Song EK., et al. "How to avoid unintended increase of posterior slope in navigation-assisted open-wedge high tibial osteotomy". Orthopedics 30.10 (2007): 127-131.

32. Sariali E and Catonne Y. "Modification of tibial slope after medial opening wedge high tibial osteotomy: clinical study and mathematical modelling". Knee Surgery, Sports Traumatology, Arthroscopy 17 (2009): 1172-1177.

33. Gaasbeek R., et al. "The influence of open and closed high tibial osteotomy on dynamic patellar tracking: a biomechanical study". Knee Surgery, Sports Traumatology, Arthroscopy 15.8 (2007): 978-984.

34. Jang KM., et al. "Unintended Rotational Changes of the Distal Tibia After Biplane Medial Open-Wedge High Tibial Osteotomy". Journal of Arthroplasty 31.1 (2016): 59-63.

35. Hinterwimmer S., et al. "Analysis of the effects of high tibial osteotomy on tibial rotation". International orthopaedics 40.9 (2016): 1849-1854.

36. Stoffel K., et al. "Patellofemoral contact pressure following high tibial osteotomy: a cadaveric study". Knee Surgery, Sports Traumatology, Arthroscopy 15.9 (2007): 1094-1100.

37. Kloos F., et al. "High tibial osteotomy increases patellofemoral pressure if adverted proximal, while open-wedge HTO with distal biplanar osteotomy discharges the patellofemoral joint: different open-wedge high tibial osteotomies compared to an extra-articular unloading device". Knee Surgery, Sports Traumatology, Arthroscopy 27.7 (2019): 2334-2344.

38. Hooper G., et al. "Oblique upper tibial opening wedge osteotomy for genu varum". Operative Orthopädie und Traumatologie 17.6 (2005): 662-673.

39. Stoffel K., et al. "Patellofemoral contact pressure following high tibial osteotomy: a cadaveric study". Knee Surgery, Sports Traumatology, Arthroscopy 15.9 (2007): 1094-1100.

40. Tian X., et al. "Distal tibial tuberosity high tibial osteotomy using an image enhancement technique for orthopedic scans in the treatment of medial compartment knee osteoarthritis". Computer Methods and Programs in Biomedicine 191 (2020): 105349. 
41. Nha KW., et al. "Uniplane medial opening wedge high tibial osteotomy relative to a biplane osteotomy can reduce the incidence of lateral-hinge fracture". Knee Surgery, Sports Traumatology, Arthroscopy 28.5 (2020): 1436-1444.

42. Nakamura R., et al. "Appropriate hinge position for prevention of unstable lateral hinge fracture in open wedge high tibial osteotomy". The Bone and Joint Journal 99.10 (2017): 13131318.

\section{Assets from publication with us}

- Prompt Acknowledgement after receiving the article

- Thorough Double blinded peer review

- Rapid Publication

- Issue of Publication Certificate

- High visibility of your Published work

Website: https://www.actascientific.com/

Submit Article: https://www.actascientific.com/submission.php Email us: editor@actascientific.com

Contact us: +919182824667 